\title{
Isolation and Molecular Docking Studies of Dihydroimperialine as Butyrylcholinesterase Inhibitor from the Bulbs of Fritillaria Imperialis
}

\author{
Muhammad Nadeem Akhtar*1, Zaheer Ul Haq ${ }^{2}$, Seema Zareena ${ }^{1}$, Noor Suhana Adzahar ${ }^{1}$ and Siti \\ Aisyah Mohamada ${ }^{1}$ \\ ${ }^{1}$ Faculty of Industrial Sciences \& Technology, Malaysia
}

${ }^{2}$ Dr.Panjwani Center for Molecular Medicine and Drug Research, International Center for Chemical and Biological Sciences, Pakistan

*Corresponding author: Muhammad Nadeem Akhtar, Faculty of Industrial Sciences \& Technology, Malaysia

ARTICLE INFO $\quad$ ABSTRACT

Received: 㗀 January 19, 2019

Published: 㠅 February 14, 2019

Citation: Muhammad Nadeem A, Zaheer Ul H, Seema Z, Noor Suhana A, Siti Aisyah M. Isolation and Molecular Docking Studies of Dihydroimperialine as Butyrylcholinesterase Inhibitor from the Bulbs of Fritillaria Imperialis. Biomed J Sci \& Tech Res 14(4)-2019. BJSTR. MS.ID.002580.
Alzheimer's disease is a progressive disorder that causes the inhibition of neurotransmitter acetylcholine in brain cells. Fritillaria imperials belong to family liliaceae, comprises several steroidal alkaloids. The subsequent extraction of ethanoic extract was subjected to column and thin layer chromatography, which led to the isolation of two steroidal alkaloids, Dihydroimperialine (1) and imperialine (2). Dihydroimperialine (1) exhibited the acetylcholinesterase and butyrylcholinestearse inhibitory activities with IC50 values as $(>500 \pm 0.23)$ and $(14.40 \pm 1.02)$, respectively. Compound 1 and imperialine (2) inhibited cholinesterase enzymes in a concentration-dependent manner. Additionally, molecular docking studies were also performed to investigate the binding mode of dihydroimperialine (1) with butyrylcholinestearse. The ligand-BChE complex were found to be stabilized by hydrophobic contacts, hydrogen bonding, and $\pi-\pi$ stacking between the compounds and amino acid residues. The main object of this study to investigate the acetylcholinesterase and butyrlcholinestrase inhibitory activity from the bulb of F. imperials. This is the first report of the isolation of dihydroimperialine (1) form natural source.

Keywords: Dihydroimperialine; Fritillaria Imperialis; Molecular Docking; Butyrylcholinesterase Inhibition Studies.

\section{Introduction}

Acetylcholinesterase is an enzyme whose primary function is to breakdown of acetylcholine into choline and Acetyl-CoA, which effects on the memory loss and other intellectual properties. The Alzheimer's Disease (AD) is associated with the loss of cholinergic neurons in the brain and the decreased level of ACh [1,2]. Fritillaria imperialis $L$ commonly known as "crown imperial". The plant usually grows in rocky slopes and amongst scrub at attitude of 1000-3000 meters in Turkey and other parts of eastern Europe. The bulb is known to be poisonous and contains low concentrations of toxic alkaloids. The genus Fritillaria belongs to the family Liliaceae, which is an important steroid alkaloid producing plant family [3]. Up to now, more than 160 alkaloids have been reported from the genus Fritillaria. A few species of Fritillaria are native to
Cyprus, Southern Turkey and Iran [4]. Among them F. roylei or F. verticillate (thembergii) commonly known as "Bei-mu" or "Pei-mu" in Chinese and "Bai-mo" in Japanese, has long been known as one of the principal Chinese crude drugs $[3,5]$ having many therapeutic applications [6]. Many species of Fritillaria are traditionally used as herbal remedies in Japan, Turkey and south Asia [7]. F. camsehatcensis [8] is another species grows in northern Japan and is an important ingredient in the diet of Hokkaido (Japan). It has also been used as antitussive, expectorant, hypotensive and for antitumor activities $[6,9,10]$.

There are several species of Fritillaria $F$ thunbergii, $F$. cirrhosa, F. persica, F. przewalski, F. Assuriensis, F. pallidiflora, $F$. delavay and F. maximowiczii used in indigenous medicine 
[11]. Several alkaloids, such as forticine, impericine, impranine, dihydroimpranine, fetisinine have already been reported from this plant, which showed acetylcholinesterase inhibitory activity [7,12-14]. Butyrylcholinesterase (E.C. 3.1.1.8), metabolizes cocaine to the water-soluble inactive compounds ecgonine methyl ester and benzoic acid [15]. The normal level of BChE varies among individuals and is dependent on age, state of health, exposure to environmental toxins and genetic factors. Low levels of BChE are associated with cocaine-induced cardiac and related complications [16]. Furthermore, deficiency of BChE shifts the metabolism of cocaine to norcocaine, a metabolite with anesthetic and cardiotoxic properties and benzoylecgonine, a metabolite that causes vasoconstriction $[16,17]$. BChE is distinguished from other esterases by a high affinity for cholinesterase and their thio analogs [17]. It has also been found that butyrylcholinesterase inhibition may also be an effective tool for the treatment of AD and related dementias [17]. Availability of the X-ray crystal structure of butyrylcholinesterase with butyrylcholine (PDBcode: 1P0P) prompted us to perform molecular docking studies. To further explore the binding mechanism of compound 1, molecular docking studies were carried out by automated GOLD docking software.

\section{Materials and Methods}

\section{General}

Optical rotations were measured on a Jasco DIP-360 digital polarimeter by using $10 \mathrm{~cm}$ cell tube. IR spectra were recorded on a Jasco A-302 IR spectrophotometer. 'H-NMR spectra were recorded on Bruker $500 \mathrm{MHz}$ NMR spectrometer and chemical shifts were calculated with reference to $\mathrm{CDCl}_{3}$ (7.25). ${ }^{13} \mathrm{C}$-NMR spectra were recorded at $125 \mathrm{MHz}$ on a Bruker $\mathrm{AM} 500 \mathrm{MHz}$ NMR spectrometer. Mass spectra were recorded on a Varian MAT 312 double focusing spectrometer, connected to an IBM-AT compatible PC computer system. Column chromatography was performed on silica gel (70-270 mesh, ASTM, Merck) and flash silica gel (230-400 mesh, ASTM, Merck). TLC was done on percolated TLC cards (Merck) with solvent system of acetone: pet ether: diethylamine (3:6.5:0.5).

\section{Plant Material}

The plant material was already explained in our previous publications $[12,13]$. The extraction and isolation procedure is the same as described in our previous publication [13]. Column chromatography of the subfraction A (1.20 gm) afforded another subfraction B (205.6 mg). Further flash column chromatography of the subfraction B afforded the semi pure compound C (37.9 $\mathrm{mg}$ ). Semipure compound 1 was finally purified $(16.4 \mathrm{mg}$ ) by flash column chromatography including compound 2 (9.0 mg) by using acetone-hexane mixture containing a few drops of diethylamine. The physical and spectroscopic data of compound 1 are given below:

Dihydroimperialine (1): Amorphous powder from chloroform (16.4 mg), []D $25=-16^{\circ}\left(\mathrm{c}=0.5, \mathrm{CHCl}_{3}\right)$. IR $\left(\mathrm{CHCl}_{3}\right)$ umax $\mathrm{cm}^{-1}$ : 3415-3409 (OH stretching), 2975 (18), 2896 (-CH stretching).
UV $\max (\mathrm{MeOH}) \mathrm{nm}(\log \varepsilon): 351$ (2.19), 222 (3.49), 208 (3.77). MS: $\mathrm{m} / \mathrm{z}$ 431. HREI MS: $\mathrm{m} / \mathrm{z}$ (mol. formula, calcd. value): 431.4226 (calcd 431.4228 for $\mathrm{C}_{27} \mathrm{H}_{45} \mathrm{NO}_{3}$ ). MS (EI, $70 \mathrm{eV}$ ): $\mathrm{m} / \mathrm{z}$ (rel. int \%): 431[ $\left.\mathrm{M}^{+}\right]$(40), 415 (16), 414 (26), 400 (23), 388 (8), 374 (24), 234 (10), 112 (100), 98 (88). ${ }^{1} \mathrm{H}-\mathrm{NMR}\left(\mathrm{CDCl}_{3}, 400 \mathrm{MHz}\right) 1.01$ (3H, s, H-19), $1.08\left({ }^{3} \mathrm{H}, \mathrm{d}, \mathrm{J} 27,25=7.0 \mathrm{~Hz}, \mathrm{H}-27\right) 1.09\left({ }^{3} \mathrm{H}, \mathrm{s}, \mathrm{H}-21\right), 3.54$ $\left({ }^{1} \mathrm{H}, \mathrm{br}, \mathrm{m}, \mathrm{W} 1 / 2=25.0 \mathrm{~Hz}, \mathrm{H}-3\right), 3.80\left({ }^{1} \mathrm{H}, \mathrm{br}, \mathrm{d}, \mathrm{W} 1 / 2=8.0 \mathrm{~Hz}, \mathrm{H}-6\right.$

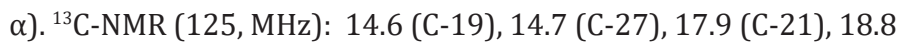
(C-16), 20.2 (C-20), 27.8 (C-25), 28.4 (C-15), 28.5 (C-24), 29.5 (C2), 31.3 (C-11), 34.6 (C-4), 39.3 (C-7), 39.4 (C-1), 39.6 (C-8), 40.9 (C-14), 41.8 (C-13), 43.8 (C-17), 48.1 (C-5), 57.7 (C-9), 59.6 (C-18), 61.3 (C-26), 63.6 (C-22), 70.9 (C-20), 71.9 (C-3), 73.3 (C-6).

\section{Cholinesterase Inhibition Assay}

The AChE and BChE inhibiting activities were measured by spectrophotometric method developed by Ellman [18]. Electric-eel AChE (EC 3.1.1.7), horse-serum BChE (E.C 3.1.1.8), acetylthiocholine iodide, butyrylthiocholine chloride, 5, 5'-dithiobis (2-nitrobenzoic acid) (DTNB), and galanthamine were purchased from Sigma (St. Louis, MO, USA). All the other chemicals were of analytical grade. Standard operational assay protocol has been described previously [19]. All the kinetic experiments were performed in 96-well microtitre-plates by using Spectra Max 340 (Molecular Devices, CA, USA). The rate of the enzymatic reaction [18] was measured by the following equation.

\section{Determination of IC50 Values}

The concentration of compounds that inhibited the hydrolysis of substrates (acetylthiocholine and butyrylthiocholine) by $50 \%\left(\mathrm{IC}_{50}\right)$ was determined by monitoring the effect of various concentrations of the compound in the assays on the inhibition values. The $\mathrm{IC}_{50}$ values (inhibitor conc. that inhibits $50 \%$ activity of AChE and BChE) were then calculated using the EZ-Fit Enzyme Kinetics program (Perrella Scientific Inc., Amherst, USA).

\section{Molecular Docking Methods}

Pretreatment of Protein. The high-resolution crystal structure of butyrylcholinesterase in complex with butyrylcholine was obtained from the Protein Data Bank (PDB ID: 1P0P) [20]. All hydrogens were first added into the PDB using the SYBYL program package, version 6.9 [21]. Protonation states were set according to the program, based on the likelihood that the residues would be charged at physiological $\mathrm{pH}$, together with their chances to form hydrogen bonds with the surrounding environment. All water coordinates and metal were removed from the protein file. Important residues, especially in the binding site were visually inspected and corrected according to charge and according to atom and bond type, especially the $\mathrm{pH}$ of lysines, arginines, aspartates and glutamates.

\section{Pretreatment of Ligand}

The ligand that was selected for the docking studies was drawn using the sketch module of SYBYL. Ligand was inspected and refined 
to correct stereochemistry and atom and bond type according to GOLD specifications. In order to obtain lowest energy conformation of the ligand, the overall geometry optimization was carried out by Powell method [22] using Tripos force field with a convergence criterion of $0.05 \mathrm{kcal} / \mathrm{mol}$. A by giving 1,000 iterations. Charge distributions were calculated by the Gasteiger-Marsili method [23].

\section{Docking in GOLD}

The GOLD software (Version 3.0) [24] was used to dock the compound onto the active site of $\mathrm{BChE}$ in order to determine the probable binding conformation of inhibitor. The scoring of the dockings was based on the scoring functions implemented in the programs. In the Gold runs, the Gold score scoring function was used. The search area in the docking runs was limited to include the cavity that forms the active site of the protein and parts of the so-called hydrophobic pocket adjacent to the active site region, which is docking region and enclosed by a sphere of $10 \AA$ centered on the center of gravity of the butyrylcholine (experimental ligand). In each case, 100 conformations of the ligand were produced and clustered by similarity. Poses were evaluated using Gold score. To test the reliability of the poses generated by GOLD, the ability to reproduce the experimental binding mode of butyrylcholine was tested. The experimental ligand was taken out of the X-ray structure, and a new conformation of butyrylcholine was docked back into the binding site using the settings above. An average rmsd value of $1.5 \AA$ between the 10 calculated poses and the experimental pose indicates a reliable prediction of the binding mode. Threedimensional structure building and all modeling were performed using on Intel ${ }^{\circledR}$ Xenon ${ }^{\circledR}$ Quad $^{\mathrm{TM}}$ core processor running under opens USE 11.0 LINUX environment.

\section{Results}

The chloroform fraction was eluted from the column chromatography with hexane-acetone (65:35\%) mixtures and compound 1 was isolated as a colorless powder. The IR spectrum of compound 1 showed strong absorption bands between $3409-3415 \mathrm{~cm}^{-1}$ for the hydroxyl group and at $2975 \mathrm{~cm}^{-1}$ for trans-quinolizidine moiety [25]. The EI-MS of compound 1 exhibited the $\left[\mathrm{M}^{+}\right]$at $\mathrm{m} / \mathrm{z} 431.4226$, in agreement with the formula $\mathrm{C}_{27} \mathrm{H}_{45} \mathrm{NO}_{3}$ (calcd. 431.4228), suggesting six degrees of unsaturation in the molecule. The mass spectrum of compound 1 also showed important fragments at $\mathrm{m} / \mathrm{z} 431$, $415,414,388,386,374,234,112$ and 98 . The base peak at $\mathrm{m} / \mathrm{z}$ 112 resulted from the cleavage of the C-20/C-22 and C-13/C-18 bonds, suggesting the presence of a heteroatom at the junction of rings $\mathrm{E}$ and $\mathrm{F}$ [26]. The ${ }^{1} \mathrm{H}-\mathrm{NMR}$ spectrum $\left(\mathrm{CDCl}_{3}, 500 \mathrm{MHz}\right)$ of compound 1 exhibited signals for three methyl groups. Two $3 \mathrm{H}$ singlets, resonating at $\delta 1.01$ and 1.09 , were assigned to the $\mathrm{C}-19$ and $\mathrm{C}-21$ methyl protons, respectively. A $3 \mathrm{H}$ doublet at $\delta 1.08\left(\mathrm{~J}_{27,25}=7.0 \mathrm{~Hz}\right)$ was assigned to the $\mathrm{C}-27$ methyl protons. Two downfield signals appearing at $\delta 3.54$ (br., $\mathrm{m}, \mathrm{W} 1 / 2=24.0 \mathrm{~Hz}$ ) and $3.80(\mathrm{~W} 1 / 2=8.2$ $\mathrm{Hz}$ ) were assigned to the $\mathrm{C}-3$ and C-6 protons, respectively $[12,13]$. The spectral data of compound 1 was identical to the earlier reported data of dihydroimperialine a reduced derivative of imperialine (2) $[27,28]$. The 13C-NMR ( $\mathrm{CDCl}_{3}, 100 \mathrm{MHz}, \mathrm{BB}$ and DEPT, Table 1) spectra showed signals for all 27 carbon atoms. Two downfield signals resonating at 71.9 and 73.3 were assigned to the $\mathrm{OH}$-containing C-3 and C-6 carbons atoms, respectively. Two quaternary carbons at 35.5 and 70.9 were assigned to the C-10 and C-20 carbon atoms, respectively (Figure 1 ).

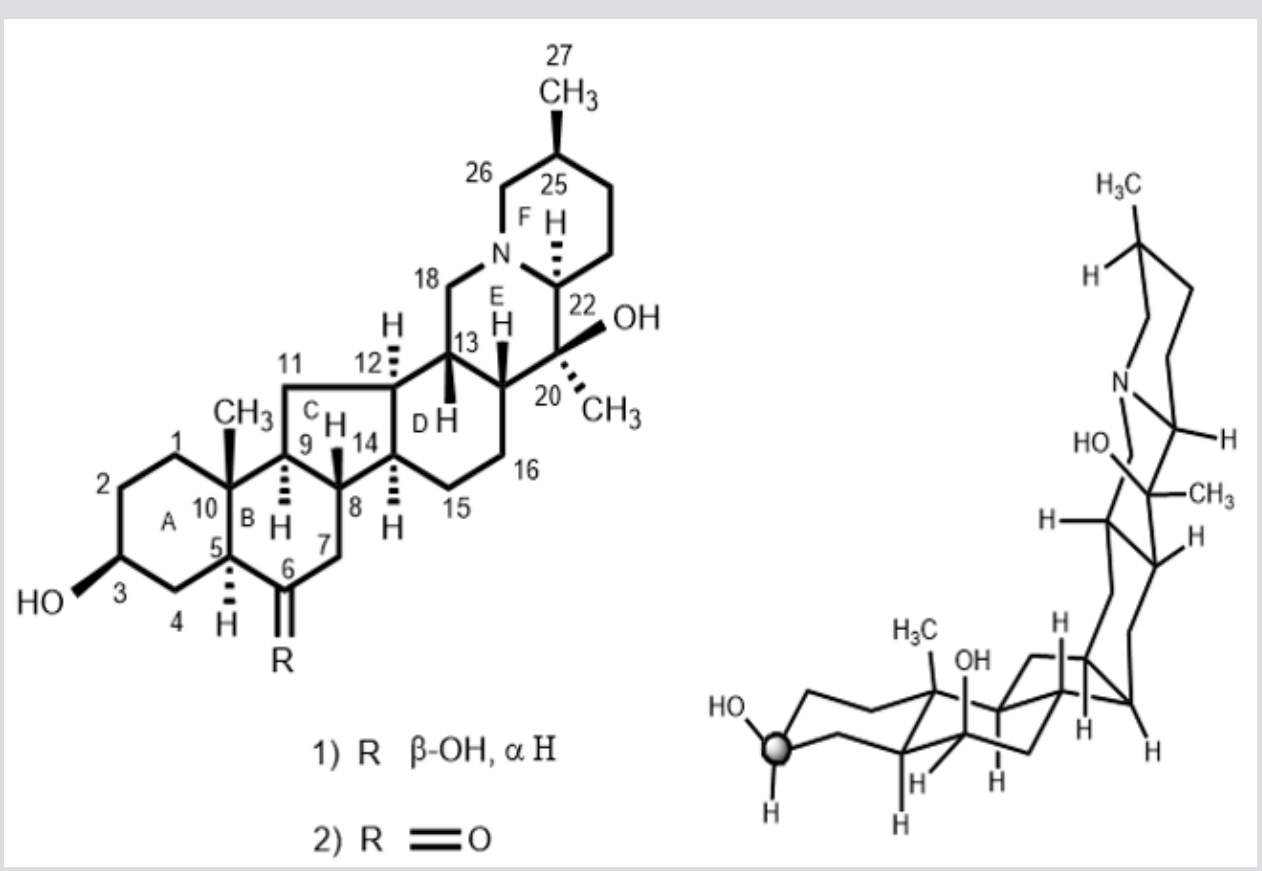

Figure 1: Chemical and structure of dihydroimperialine (1) and its perspective view. 
The stereochemistry at the asymmetric center was elucidated on the basis of the 1H-NMR and 13C-NMR chemical shifts comparisons with imperialine (2). For the direct comparison of dihydroimperialine (1), known compound imperialine (2) was reduced with $\mathrm{NaBH} 4$ to obtain dihydroimperialine and compared with the naturally isolated dihydroimperialine (1). The mass spectra of compound 1 exhibited the ions at $\mathrm{m} / \mathrm{z}$ at $431,416,415$, 400, 386, 387, 234, 180, 155,154, 124 112, 98, and 55, like the mass fragmentation patterns reported for found in imperialine (2), zygacine and eduradine [29]. The base peak at m/z 112 and 98 indicated the presence of cevanine-type steroidal alkaloids [29]. Dihydroimperialine (1) was obtained as an amorphous colorless powder by column chromatography of the chloroform extract of $F$. imperialis and identified as $\left({ }^{20} \mathrm{~S},{ }^{22} \mathrm{~S},{ }^{25} \mathrm{~S}\right)-5 \alpha$-cevanin-3 $\beta, 6 \beta$-diol.

For molecular docking studies, initially to test the validity of Gold docking program, at the first stage the crystal structure of the BChE-Butyrylcholine complex (PDB ID: IP0P) was successfully reproduced. The root-mean-square deviation (RMSD) of the docked confirmation to the experimental confirmation was around $1.0 \AA$, Figure 2 suggesting a high reliability of GOLD in reproducing the experimentally observed binding mode of buytrylcholinesterase. The quality level of the docking complex was similar to that of the original crystal structure. Additionally, all top rank conformations were clustered at the active site with almost identical confirmations see Figure 2. This result suggested that the protocol applied for the docking simulation was sufficient for further analysis and could be accepted for virtual screening purposes in our study. Dihydroimperialine (1) was successfully docked on the active site of BChE keeping the same docking protocol used for reference ligand (Figure 3). Dihyroimperialine (1), which has a rigid structure, comprises six rings with one hydrogen bond accepter group at ring $\mathrm{E}$ and three hydrogen bond donar groups at ring $\mathrm{A}, \mathrm{B}$ and $\mathrm{E}$. The rigid steroidal backbone of compound 1 enters the aromatic gorge through the six-membered ring $\mathrm{A}$, and thus, placed the ring $\mathrm{A}$ in the bottom of the gorge near $\mathrm{Thr}_{120}$.

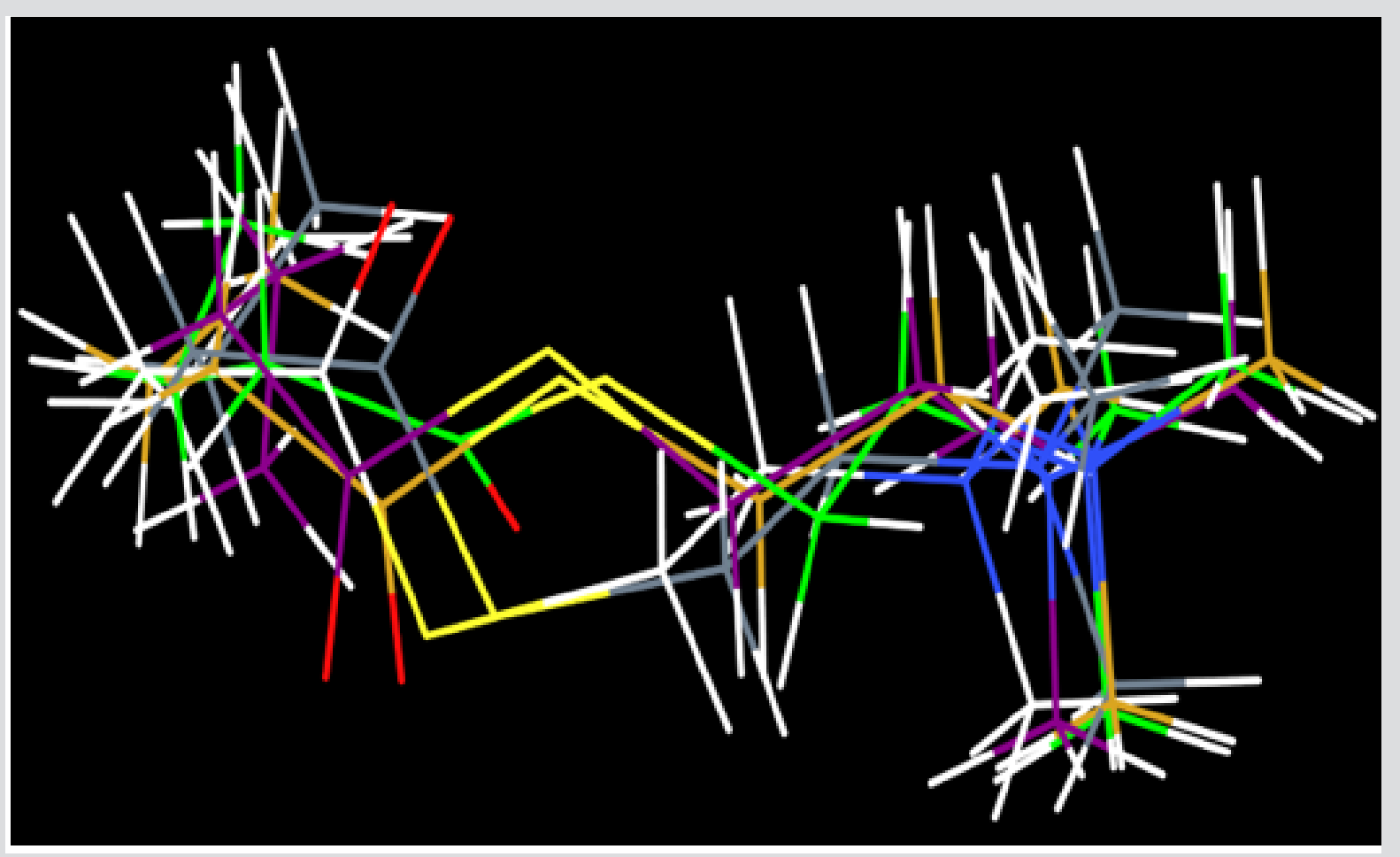

Figure 2: Evaluation Of GOLD docking software; superimposition of top 4 poses showed almost the same bonding pattern as that of butyrylcholine.

The ring A was stabilized by hydrogen bonding between hydroxyl group A and terminal hydroxyl group of Thr120 (3.07 Å) [30]. Another much stronger hydrogen bond was observed between the hydroxyl group B and the peptidic carbonyl atom of $\operatorname{Pro}_{285}(2.82$ Å) (Figure 3). Additionally, the center of ring A into gorge of $\mathrm{BChE}$ is stabilized by cation- interaction contributed by $\mathrm{Asp}_{70}$. The ring $\mathrm{B}$ forms - interaction to one of the aromatic amino acid residues of gorge $\mathrm{Tyr}_{332}$. Compound 1 was evaluated for its butyrylcholinesterase inhibitory activity and found to be active against the butyrylcholinesterase enzyme with IC50 $14.4 \pm 1.0(\mu \mathrm{M})$. The inhibitory activity and $\mathrm{IC}_{50}$ values are given in Table 1 . Conclusion: This is the first report of the isolation of dihydroimperialine (1) form natural source and molecular docking studies showed the sign for future drug discovery for Alzheimer's disease. 


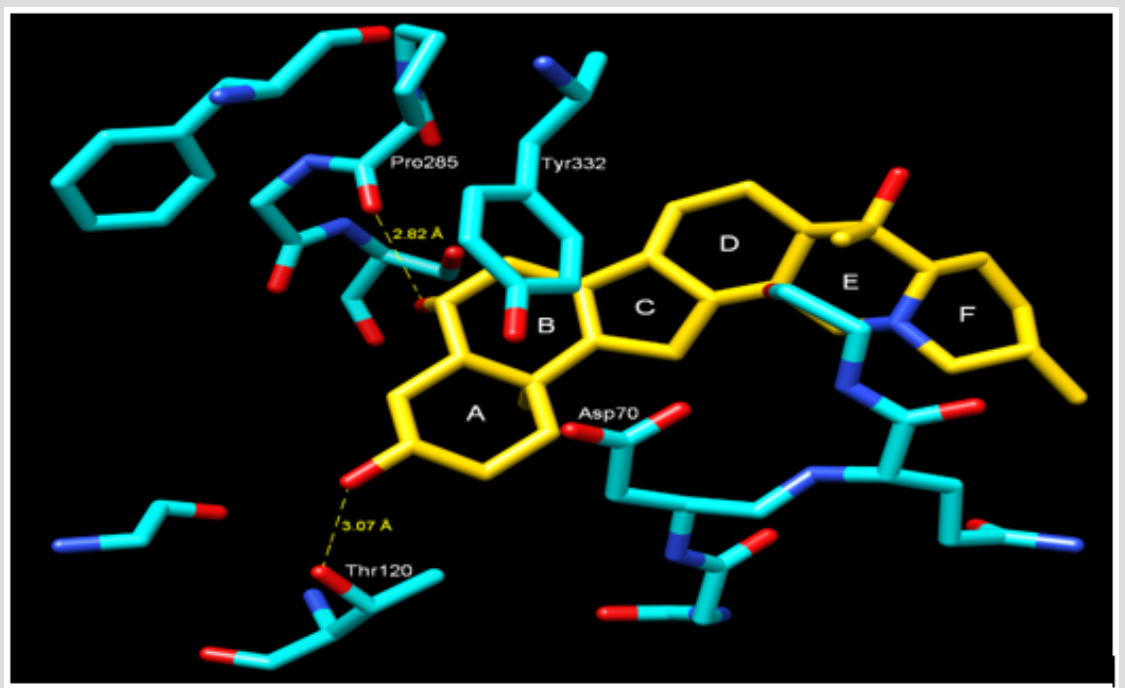

Figure 3: Docking of compound Dihydroimperialine (1) and BChE, showing the hydrogen bonding, cation- $\Pi$ and $\Pi-\Pi$ interactions. Amino acid residues in numbered are dominant residues that are involved in interactions.

Table 1: Summary of the In-vitro Quantitative Inhibition of AChE and BChE of Compounds 1 and 2.

\begin{tabular}{|c|c|c|}
\hline \multirow{2}{*}{ Compounds } & \multicolumn{2}{|c|}{ (IC $_{\mathbf{5 0}} \pm$ SEM)A $[\boldsymbol{\mu M}]$} \\
\cline { 2 - 3 } & AChE & $(14.40 \pm 1.02)$ \\
\hline Dihydroimperialine (1) & $>500$ & $(58.3 \pm 0.23)$ \\
\hline Imperialine (2) $^{*}$ Galanthamine) $^{\mathrm{B}}$ & $>500 \pm 0.23$ & $(8.50 \pm 0.08$ \\
\hline
\end{tabular}

\section{Acknowledgement}

We are thankful to the Universiti Malaysia Pahang (www.ump. edu.my) and Ministry of Higher Education of Malaysia for the award of internal grants (RDU 150109).

\section{References}

1. Newman MB, Nazian SJ, Sanberg PR, Diamond DM, Shytle RD (2001) Corticosterone-attenuating and anxiolytic properties of mecamylamine in the rat. Prog Neuropsychopharmacol Biol Psychiatry 25(3): 609-620.

2. Ferreira Vieira TH, Guimaraes IM, Silva FR, Ribeiro FM (2016) Alzheimer's Disease: Targeting the Cholinergic System. Current Neuropharmacology 14(1): 1-15.

3. Kitajima J, Komori T, Kawasaki T, Schulten HR (1982) Basic steroid saponins from aerial parts of Fritillaria Thunbergii. Phytochemistry 21(1): 187-192.

4. Ori K, Mimaki Y, Sashida T, Njkaido T, Ohmoto T, Masuko T (1992) Cerveratrum Alkaloids from Bulbs of Fritillaria persica. Phytochemistry 31(10): 3605-3607.

5. Kitajima J, Noda N, Ida Y, Miyahara K, Kawasaki T (1981) Steroid Alkaloids of Fresh Bulbs of Fritillaria thunbergii MIQ. and Crude Drug "BAI-MO" prepared therefrom. Heterocycles 15: 791-793.

6. Chi Y, Kao, Y S, Chang KJ (1936) The Alkaloids of Fritillaria roylei I Isolation of Peimine. J Am Chem Soc 58(7): 1306-1307.

7. Li HJ, Jiang Y, Li P (2006) Chemistry, Bioactivity and Geographical Diversity of Steroidal Alkaloids from the Liliaceae family. Natural Product Report 23(5): 735-752.

8. Kaneko K, Nakaoka U, Tanaka M, Yoshida N, Mitsuhashi H (1981) Two Steroidal Alkaloids, Hapepunine and Anrakorinine, from the mature Fritillaria camtschatcensis. Phytochemistry 20(1): 157-160.
9. Ito S, Fukazawa Y, Miyashitam M (1976) Structure of Imperialine. Tetrahedron Letters 17(36): 3161-3164.

10. Jiang Y, Li H, Li P, Cai Z, Ye W (2005) Steroidal Alkaloids from the bulbs of Frtillaria puqiensis. Journal of Natural Product 68(2): 264-265.

11. Perry LM (1980) Medicinal Plants of East and Southeast Asia: Attributed Properties and Uses. The MIT Press Cambridge, Massachusetts London and England, pp. 236-237.

12. Akhtar MN, Atta ur Rahman, Choudhary MI, Sener B, Erdogan I, et al. (2003) New Class of Steroidal Alkaloids from Fritillaria imperialis. Phytochemistry 63(1): 115-122.

13. Atta ur Rahman, Akhtar MN, Choudhary MI, Tsuda Y, Sener B, et al. (2002) New Steroidal Alkaloids from Fritillaria imperialis and Their Cholinesterase Inhibiting Activities. Chem Pharm Bull 50(8): 1013-1016.

14. Akhtar MN, Lam KW, Abas F, Ahmad S, Shah SAA, et al. (2011) NH New Class of Acetylcholinesterase Inhibitors from the stem bark of Knema laurina and their Structural Insight. Bioorganic Medicinal Chemistry Letter 21(13): 4097-4103.

15. Tougu V (2001) Acetylcholinesterase: mechanism of catalysis and inhibition. Current Medicinal Chemistry 1(2): 155-170.

16. Perry EK (1986) The Cholinergic hypothesis ten years on. British Medical Bulletin 42(1): 63-69.

17. Yu SQ Holloway HW, Utsuki T, Brossi A, Greig NH (1999) Synthesis of Novel Phenserine-Based-Selective Inhibitors of Butyrylcholinesterase for Alzheimer's Disease. Journal of Medicinal Chemistry 42(10): 18551861.

18. Ellman GL, Courtney KD, Andres V, Featherstone RM (1961) A New and Rapid Colorimetric Determination of Acetylcholinesterase Activity. Biochemical Pharmacology 7(2): 88-90.

19. Choudhary MI, Devkota KP, Nawaz SA, Shaheen F, Atta ur Rahman (2004) Cholinesterase-Inhibiting New Steroidal Alkaloids from Sarcococca 
hookeriana of Nepalese Origin. Helvetica Chimica Acta 87(5): 10991108.

20. Bernstein FC, Koetzle TF, Williams GJ, Meyer E, Brice MD, et al. (1977) The protein databank: A computer based archival file for macromolecular structures. J Mol Biol 112(3): 535-542.

21. SYBYL Version 6.9 (1998) Molecular modeling software. Tripos Associate Ltd St Louis.

22. Clark M, Cramer RD III, Van Opdenbosch N (1988) Validation of the general purpose Tripos 5.2 force field. J Compu Chem 10(8): 982-1012.

23. Kramer B, Rarey M, Lengauer $T$ (1999) Evaluation of the FlexX incremental construction algorithm for protein-ligand docking. PROTEINS: Structure, Function and Genetics 37(2): 228-241.

24. Rarey M, Kramer B, Lengauer T, Klebe G (1996) A fast flexible docking method using confirmational ensembles. J Mol Biol 261: 470-489.

ISSN: 2574-1241

DOI: 10.26717.BJSTR.2019.14.002580

Muhammad Nadeem Akhtar. Biomed J Sci \& Tech Res

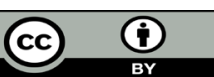

This work is licensed under Creative Commons Attribution 4.0 License

Submission Link: https://biomedres.us/submit-manuscript.php
25. Bohlman F (1958) For the Configuration Determination of Quinolizidine Derivatives. Chemistry in Britain 91: 2157-2167.

26. Boit GH (1954) Uber Imperialin, I Mitteil. Chemistry in Britain 87: 472475.

27. Katritzky AR (1963) Physical Methods in Heterocyclic Chemistry. Academic Press, New York, USA 46: 253-254.

28. Kaneko K, Katsuhara T, Mitsuhashi H, Chen YP, Hsu HY, et al. (1985) Isolation and Structure Elucidation of New Alkaloids from Fritillaria Delavayi. Franch Chem Pharm Bull 33(6): 2614-2617.

29. Nuriddnov RN, Saidkhodzahaev AI, Shakirov R, Yunusov S Yu (1968) The Structure of Korsine. Khimiya Prirodnykh Soedinenii 4(3): 161-168.

30.Zaheer ul haq, Wellenzohn B, Liedl KR, Rode BM (2003) Molecular Docking Studies of Natural Cholinesterase-Inhibiting Steroidal Alkaloids from Sarcococca saligna. J Med Chem 46(23): 5087-5090.

\begin{tabular}{ll} 
BIOMEDICAL & Assets of Publishing with us \\
RESEARCHES & - Global archiving of articles \\
& - Immediate, unrestricted online access \\
\hline ISSN: 2574-1241 & - Rigorous Peer Review Process \\
\end{tabular}

